\title{
Polemički stil A.G. Matoša
}

\begin{abstract}
Bagić Krešimir, Polemički stil A.G. Matoša (A.G. Matoš’s Polemical Style). „Poznańskie Studia Slawistyczne” 7. Poznań 2014. Publishing House Science and Innovate, pp. 21-36. ISBN 978-83-63795-79-5. ISSN 2084-3011.
\end{abstract}

Antun Gustav Matoš is the father of the Croatian literary polemics. By confronting his contemporaries, he shaped a unique style of polemicizing which is characterized by straightforwardness, wit, elegance of speech and artistry. This style is based on various procedures which Matoš used in his polemics as well as on different textual patterns through which he articulated his polemical thought. The paper descibes and exemplifies seven stylistic procedures (portraying in oposition, polemical quote, polemical naming, polemical verb, polemical maxim, word play, polemical point) and eight textual patterns (literary criticism, fictitious dialogue, comical story, polemical poem, aphorism, drama, polemical epistle). The opulence of Matoš's style produces a polemics which is both carnevalesque and fictional. He brings together what is seemingly incompatible - the polemics which is based on the truth principle and fiction which is essentially indifferent towards that principle.

Keywords: Antun Gustav Matoš; fiction; polemics; procedure; style; text

Kada se 1892. devetnaestogodišnji Antun Gustav Matoš u „Viencu” oglasio pripovijetkom Moć savjesti, malo je tko mogao slutiti da počinje nastajati jedan od najvažnijih opusa cjelokupne hrvatske književnosti. Kada je 1914. Matoš umro, mnogima je bilo jasno da se u te 22 godine bitno izmijenila njezina slika te da će Matoševa zvijezda još dugo obasjavati naše literarno nebo. Rođen u petak, trinaestoga, taj je boem i austrougarski dezerter, ponavljač sedmog razreda zbog drugog reda iz hrvatskog jezika, bitno revolucionirao jezik i uspostavio nove poetičke kanone u našoj književnosti ${ }^{1}$. Ovdje ću se

1 Razdoblje hrvatske moderne moglo bi se nazvati Matoševim dobom. Neki ga autori i omeđuju godinom tiskanja njegove prve pripovijesti (Šicel 1978) i godinom njegove smrti (Košutić-Brozović 1970). 
usredotočiti na Matoševo polemičko lice, koje proviruje iza njegove znamenite rečenice: „U literaturi prijatelja nemam niti ih trebam” (Matoš 1973a: 236). Ako se nečega dosljedno držao, onda se držao tog postulata.

\section{Vrtlar koji plijevi vrt}

Matoš je polemizirao o veoma različitim temama - književnosti, politici, novinarstvu, religiji, moralu, odnosu spolova, glazbi, likovnosti, jednom zgodom i o tome tko je koga istukao u birtijskom obračunu. Među njegovim protivnicima bilo je vodećih književnika, intelektualaca i političara tog doba, ali i (danas) malo poznatih pisaca i javnih osoba. Protivnici su mu, među inim, bili: Ivo Vojnović, Tin Ujević, Janko Polić Kamov, Milan Begović, Milutin Cihlar Nehajev, Ksaver Šandor Gjalski, Mijo Radošević, Krešimir Kovačić, Milan Ogrizović, Branimir Livadić, Milivoj Dežman, Petar Petrović Pecija, Milan Marjanović, Stjepan Parmačević, Branko Vodnik, Jovan Skerlić, Albert Bazala, Kerubin Šegvić, Jovan Hranilović, Arsen Wenzelides, Vladimir Treščec, Antun i Stjepan Radić, Natko Nodilo, Frano Supilo, Josip Frank, Đuro Šurmin, Emil Groll, Adela i Andrija Milčinović, Franjo Jarmek, Dušan Plavšić, Đorđe Nastić, Milan Plut, Zvonimir Vukelić, Ivan Molinar itd. Od prigode do prigode, od protivnika do protivnika, mijenjao je polemička lica. Bio je kritičar i mistifikator, humorist i psovač, nacionalist i kozmopolit, stilist i strančar. Razlog tako širokoj aktivnosti krije se u Matoševu odnosu spram načela borbe kojega je polemika prirodni izraz. Taj je pisac borbu proglasio osnovnim preduvjetom svakog napredovanja. „Bez borbe nema razvitka” (Matoš 1973b: 143), zapisao je. Dapače, u njoj je nalazio korist za pojedinca i literaturu u kojoj takav pojedinac djeluje. $\mathrm{Na}$ jednom mjestu piše da ,u interesu razvoja svoje energije najradije (traži) protivnika, jakog protivnika za mjerilo svoje vlastite otpornosti" (Matoš 1973a: 174). Na drugom ide korak dalje pa uopćava: „Teško literaturama koje živu bez borbe. U savremenom literarnom marazmu će svaka polemika tek koristiti pravoj književnosti. Jedva čekamo kritični glas nezadovoljnika" (Matoš 1973c: 199).

Polemički se govor u njegovu opusu javlja kao važan sastojak različitih žanrova (kritike, eseja, čak i poezije). U Sabranim djelima polemikama su posvećena tri sveska s ukupno 193 polemička teksta. Dvanaesti svezak 
donosi knjigu Dragi naši savremenici, koju je sâm Matoš priredio za tisak još 1912. godine; trinaesti i četrnaesti svezak, Polemike I i Polemike II, donose u tu knjigu neuvrštene polemičke članke. U predgovoru Dragim našim savremenicima Matoš se predstavlja kao vrtlar koji plijevi u korov zarastao literarni vrt, izjednačavajući pritom važnost polemike (plijevljenja) i ,čiste” literature (sijanja, sađenja i kalamljenja): „Nije samo ono dobar vrtlar što zna sijati, saditi i kalamiti rijetko cvijeće i sočne voćke. Vrt se treba i plijeviti, da se na štetu korisnoga ne rastići čkalj, kopriva i ini drač" (Matoš 1973a: 7). Matoš je i u polemici artist. On nastoji čitatelja pridobiti i za svoju tezu i za svoj stil. Tko pobjeđuje u polemici? Na jednom mjestu kaže: „U polemici pobjeđuje onaj tko se manje ljuti” (Matoš 1973b: 133). A na drugom dodaje: „I mi na kraju pobjeđujemo, jer s e s mij e mo, i jer su na našoj strani rođeni ljubitelji šale, djeca, momci i žene, lijepe, nježne ženice" (Matoš 1973b: 173).

Uvjeren sam u dvoje: 1. da je Antun Gustav Matoš najodličniji stilist hrvatske književnosti i 2 . da se glavna obilježja njegova stila ostvaruju i u polemičkim spisima. Stoga ću pokušati opisati taj stil usredotočujući se na karakteristične postupke i na raznorodnost tekstualnih obrazaca njegove polemike.

\section{Stilski postupci}

Brojne je Matoševe spisateljske postupke moguće tretirati svojevrsnim figurama negacije, bilo da im je funkcija preosmišljavanje koje smjera nijekanju bilo da rade na izravnom osporavanju protuteksta i/ili protivnika. Upozorit ću na njih sedam.

\subsection{Portretiranje u opoziciji}

Klasičan postupak u Matoševoj kritici i polemici. U kritici pisac pomoću njega podcrtava granicu između djela o kojemu govori i svojeg čitanja tog djela, a u polemici čitatelja upućuje na nepremostiv jaz koji vlada među sučeljenim stranama. Portretiranjem u opoziciji polemički subjekt apsolutizira svoju, a minorizira protivnikovu poziciju. Matošev se polemički autoportret dopunjava od prigode do prigode. Primjerice, u sukobu s Tinom Ujevićem 
Matoš se predstavio kao Učitelj i originalan autor nasuprot Discipulusu koji je plagijator i lažac.

Umjesto učenika dobih majmuna. Umjesto đaka što ide svojim putem dobih sjenu koja me parodira. Umjesto pjesnika dovedoh na Parnas papigu koja je kriještala kao jeka moje vlastite riječi, kao travestija moje duše. (...) I reknem Discipulusu: Čujete, dragi moj, vi ste me krivo shvatili. Ja vas upućivah na vaše, ne na svoje putove. Svi drumovi vode u Rim, a ja ne marim da mi neko na tom putovanju sjedi kao usjedjelički pinčl u krilu. Vi me, dragi moj, jednostavno karikirate. Nehotice pravite iz mene bedaka. Ja nisam „Osman”, pa da me popunjavate (Matoš 1973a: 255).

Polemička razrada opreke Ja - On u pravilu sukob dvaju subjekata pretvara u sukob subjekta i objekta. Protivnik biva popredmećen, a polemički si subjekt upravo u procesu njegova popredmećenja izrađuje prigodni autoportret.

\subsection{Polemički citat}

Protivnikov se tekst citira u svrhu prokazivanja, a tekstovi autoriteta u svrhu potkrepe vlastitog mišljenja. Polemičar, citirajući, fingira poziciju znanstvenika koji dokazuje postavljenu tezu. No, dok znanstvenik želi stvarno komunicirati s tekstom koji citira, polemičar čini upravo obratno: citira da bi pokazao nemogućnost komunikacije. Polemička je ilustracija iluminacijskog karaktera jer u pravilu krivotvori semantiku citiranog materijala. U sukobu oko romana $Z a$ materinsku riječ K.Š. Gjalskoga Matoš poduzima polemičku stilističku analizu tog romana. On je zapravo popisao i polemički komentirao jezične greške i stilske nezgrapnosti koje je našao na prvih 37 stranica romana. Citirajući Gjalskijeve rečenice, spacionirao je sporne dijelove te se ta spacioniranja mogu tumačiti kao grafostilistički polemički postupak kojemu je cilj istaknuti argumentacijski materijal na kojemu se obračun temelji. Npr.:

"Gostioničar je sa svojim debelim trbušastim tijelom jedva do spi o da skoči do vrata". Str. 10. (Valjda je gostioničar pod pazuhom nosio tijelo, jer je s njim jedva dospio da skoči.) (Matoš 1973a: 36).

„Strah me je, zlo će izaći - govorio je kod zapaljene cigare Runjević”. (Kod zapaljene cigare? Možda je gdjegod u Šumadiji kakav „hotel garni” te nosi ime „K zapaljenoj cigari”.) (Matoš 1973a: 37). 


\subsection{Polemičko imenovanje}

Postupak kojim se najčešće izvodi osobni obračun. Protivniku se nadijevaju pogrdna imena, smišljaju diskvalificirajuće karakterizacije kako bi ga se potpuno „razoružalo”. Ta pogrdna imena i te karakterizacije aludiraju na protivnikovo neznanje, nemoralnost, sumnjivo političko opredjeljenje, privatnost itd. Kod Matoša ta imenovanja povremeno nadrastaju i maniriziraju polemičku informaciju. U najartističnijoj polemici hrvatske književnosti, onoj s Ujevićem, Matoš je Tina nazvao „mladim apašem”, „literarnim fakinom”, „Augustinom Huljevićem - pardon - Ujevićem”, „fakinskim literarnim parazitom”, ,neugodnim balavačkim nametnikom”, ,discipulusom Augustinusom”, „literarnim špiclom i potkazivačem”, „nadobudnim mladencem”, „mladim hidalgom”, „lucprdom Augustinom”, „Uševićem”, „Huljevićem”, „džebrakom”, „literarnim Herostratom”, „žutokljuncem”, „pretencioznim deranom” itd. Kamova u polemičkoj vrućici proziva „pjesnikom bluda”, „pjesnikom mržnje”, „pjesnikom psosti”, „gorostasnim bludnikom”, „sterilnim rasplodnikom”, ,pjesnikom psovača”, „sadikom”, „masochistom”, „kočijašem”, „kretenom”, „budalom”, „,anarhistom”, „šeretbudalom”, ,pjesnikom smrada”, „dijaboličarom idiotske poetike i kretenske retorike”, „pjesnikom grijeha”, „pjesnikom kraste”, „,naprednjačkim hrvatskim Baudelaireom”, „pjesnikom azma i protoplazma”, „pjesnikom izma i nihilizma”, ,pjesnikom packe” i „,megalomanskim nadripoetom”.

Stalno polemizirajući, Matoš je stvorio i nekoliko imena kojima je kanonizirao odnos spram nekih protivnika. Tako je Stjepana Parmačevića uporno zvao ,gospođica Spermačević” i ,primalja Parmačević”, M. Ogrizovića „Ogrizina”, časopis „Pokret”: „Pokržet” i „list intelektualnih razbojnika”, njegove suradnike ,pokreteni” i ,ppokretenčići” itd. Što je polemika bivala manje problemska, a više parodijska, polemičkih je imenovanja bivalo sve više.

\subsection{Polemički glagol}

Govoreći o protivniku i njegovu tekstu, polemičar tendenciozno imenuje njegove namjere, argumente, napade i obranu. Kada protivnik prigovara, polemičar kaže da „napada”; kada argumentira, polemičar kaže da „laže” ili „,izmišlja”; kada se brani, polemičar kaže da „roni suze” 
itd. ${ }^{2}$ Tako se već na razini ,imenovanja” protivnikovih radnji događaju specijalni obrati koji apeliraju na čitateljevo razumijevanje i osjetljivost. No Matoš se ne zadovoljava upotrebom tipiziranih glagola. Manirizira tekst time što rabi i brojne druge glagole koji još ekspresivnije poništavaju važnost protivnikovih tvrdnji i argumenata. Navest ću tek dio polemičkih glagola (i sintagmi) kojima Matoš opisuje što čine njegovi suparnici. Kada govore, oni: ,anatemišu”, „bezočno lažu”, ,bojkotiraju”, „brbljaju”, „,bulazne”, „,buše i ruju”, „,ciče i pište”, ,„čavrljaju”, „denunciraju”, „dižu hajku”, „drobe”, „džapaju”, ,glagoljaju”, ,govore neistine”, ,grde”, ,gunđaju i cijede”, „hine”, „hvale se”, ,insinuiraju”, ,izmišljaju”, ,izmotavaju se”, ,izvraćaju”, „kleveću”, „kradu”, „kraduckaju”, „krekeću”, „kukavno sumnjiče”, „lažu”, „ljute se”, „mažu i farbaju”, „naivno kore”, „napadaju”, „,naučno kritikuju”, „odgovaraju”, „opanjkavaju”, „optužuju”, ,otimaju koricu kruha”, „plagiraju”, ,pobijaju lažima”, ,pljuju”, ,,podmeću”, ,ponižavaju”, ,popapučuju se”, „potkazuju”, „potvoravaju”, „prepisuju”, ,prijete”, ,propovijedaju”, „rade o glavi”, „raspištoljuju se”, „razveseljuju ga”, „rovare”, „rugaju se”, „sipaju drvlje i kamenje”, „skakuću”, ,sline od tuge”, ,spletkare”, „sprdaju se”, „šaraju”, „,̌vefluju”, „trabunjaju”, ,toroču”, ,trube”, „trućaju”, „truj-truj-trućaju”, „vrijeđaju”, ,zaboravljaju spomenuti”, „,zameću trag”, ,žigošu” itd.

Naravno, sasvim su drugi glagoli i sintagme u igri kad Matoš govori što on čini svojim protivnicima. Matoš ih tako među ostalim: „ćuška”, „dijeli im vruće zaušnice”, „hobla ih”, „lomi im zube”, „mesari ih”, „maže im leđa”, „mijesi ih”, „odrapljuje”, „,opatrnjuje”, ,otpuhuje ih”, ,pegla i pijegla”, ,pere ih”, ,,predaje ih javnosti”, „biberi im i soli” itd. Polemički glagoli bjelodano otkrivaju temeljne odlike polemičkog subjekta: otkrivaju da je kao karakter autoritaran prema suparniku i samodopadan, a kao pisac (koji kalkulira s potporom publike) pristaša izravnosti i humorističkog ili ironijskog koda.

\subsection{Polemička maksima}

Ako je aforizam ,intelektualna poslovica”, polemička je maksima prigodni aforizam kojim se aludira na protivnikovo ponašanje i mišljenje.

${ }^{2}$ Karel Čapek taj postupak naziva drugom figurom (Termini) borbe perom i zaključuje da joj je cilj protivnika prikazati kao ,nepodnošljivog, neodgovornog i nekako nastranog” čovjeka (Čapek 1967: 44). 
Polemička maksima poopćava protivnikovo ponašanje u sredini u kojoj se sukob događa. Polemičar se njome predstavlja kao naivan i hrabar čovjek koji se $-u$ ime svih - bori protiv opće pošasti. Temelji se na paradoksu, kontrastu i antitezi. Njome se, ovisno o konkretnoj diskurzivnoj strategiji, najavljuje ili okončava sukob. Npr.:

On toliko voli originalnost u svojim recenzijama, da čak i u njima ima - mojih originalnosti, pak bih vruće želio da budem što manje originalan u djelima Augustina Ujevića (Matoš 1973a: 259).

Ako su svi atentati na jezik i sintaksu u romanu štamparski lapsusi, Za materinsku riječ je jedna ogromna štamparska pogreška, najveća poslije Guttenberga (Matoš 1973a: 47).

Ako nemamo književnosti, mi barem imamo književnika! (Matoš 1973a: 53).

Da je umjetnost imitacija, Begović i majmuni bili bi umjetnici (Matoš 1973b: 134).

Najbolji Hrvati su Srbi (Matoš 1973c: 14).

U Hrvatskoj je naime kao u nebu. Posljednji su na prvim mjestima (Matoš 1973c: 179).

\subsection{Jezične igre}

Ludički Matoš obračun često izvodi jezičnim igrama. One slijede njegovu polemičku argumentaciju i pretvaraju se u prigodne (razorne!) figure negacije. Među brojnim jezičnim igrama oprimjerit ću pravopisnu figuru i sintaktičku reduplikaciju ${ }^{3}$.

Pravopisna figura: nestandardna poraba pravopisa koja ističe polemičnost rečenoga. Matoš rado rabi uskličnike i upitnike kao intenzifikatore osporavajućeg čuđenja nad protivnikovim rečenicama. U polemikama s časopisom „Pokret” često ironijski aludira na fascinaciju njegovih urednika i suradnika češkim političarem i piscem Tomašem Masarykom. Pravopisna figura nastaje tako što fonem $\mathrm{r}$ iz njegova prezimena najprije ludički prispodobljuje češkom fonemu, potom zapisuje približan izgovor toga drugog fonema rž zbog čega pan Masaryk postaje „,pan Masaržyk”, a zatim „stradavaju” i svi njegovi hrvatski sljedbenici: „Pokret” postaje „Pokržet”, njegovi suradnici „pokržetaši”, Zofka Kveder „Zofka Kvederž”, Stjepan Parmačević „pržimalja Spermačević”, Wilder „Wilderž”, realisti „ržealisti”,

${ }^{3}$ U njegovoj se polemičkoj praksi mogu naći i primjeri zvukovne i smisaone igre riječima, kalambura, paronomazije, paregmenona, rime i tsl. (Bagić 2012). 
naprednjaci „,napržednjaci”, Gjalskijeva „Materinska riječ” - „Materžinska riječ" itd.

Sintaktička reduplikacija: temelji se na ponavljanju ključne riječi u rečenici kojom se najjasnije imenuje protivnik ili kakva osobitost njegova pisanja ili ponašanja. Funkcija je sintaktičke reduplikacije intenzifikacija uporišnih točaka obračuna.

(„Pokret” je) podlac, podlac i po sto puta podlac... (Matoš 1973b: 98).

Poslednja reč hrvatskog kompromisnog i kompromitovanog modernizma zove se dakle Bazala, Albert Bazala, dr. Albert Bazala (Matoš 1973c: 36).

(...) kakvim li se sve đubretom ne „pere” taj --- taj --- taj Ogrizović! (Matoš 1973c: 125).

\subsection{Polemička poenta}

Nakon okončane polemike ili koje njezine dionice Matoš počesto iskazuje uvjerenje kako je javnost nesumnjivo stala na njegovu stranu. To čini zaključnom rečenicom u kojoj se, tobože nehajno, odnosi prema protivni$\mathrm{ku}$, temi spora i samoj polemici. Zapravo, zaključak postaje svojevrsnom polemičkom poentom, koja preoznačava (humorom i ironijom) čitav tekst. Budući da je protivnik u dotadašnjem tekstu razoružan i ,ispijeglan”, polemička je poenta namijenjena čitateljima.

A Pokretu više ne odgovaram ako ostanu njegovi napadaji anonimni i - naivni (Matoš 1973a: 34).

I tako dalje (Matoš 1973b: 121).

Umjesto odgovora ostavljam g. Marjanovića na uglu (Matoš 1973c: 158).

Fra Cherubin me s a d a tuži... Tako on polemiše! (Matoš 1973c: 170).

Mnogo babica, k--o dijete! (Matoš 1973c: 218).

\section{Tekstualni obrasci Matoševih polemika}

Matoševa polemička misao jednom izrasta iz intelektualne skepse, drugi put iz literarne imaginacije, treći put iz ludičkog poigravanja sa svime oko sebe. Različiti su poticaji uzrok brojnosti i raznovrsnosti tekstualnih obrazaca njegovih polemičkih iskaza. Ta karnevalizacija polemike svjedoči o osjetljivosti koja pojedinom napadaju pridružuje i primjerenu 
diskurzivnu formu. U njegovu sam polemičkom opusu uočio osam tekstualnih obrazaca.

\subsection{Književna kritika}

Kritičar Matoš koncentrira se na osporavanje djela, poetike, autora. Osporavanje je totalno: počinje od jezika i stila, a završava prigovorima o nakaznoj kompoziciji, banalnom literarnom mišljenju i ljudskim manama autora dotičnog djela. Polemička je Matoševa kritika obično uvodni tekst u obračun s autorom zanijekanog djela, njegovim štovateljima, poetičkim i idejnim istomišljenicima. Negativno je, među ostalim, ocijenio djela K.Š. Gjalskoga, J.P. Kamova, M. Begovića, M. Ogrizovića, M. Marjanovića, B. Vodnika, K. Šegvića, J. Hranilovića, Mije Majera itd., a te su ocjene potom postajale razlogom za polemiku.

\subsection{Fiktivni dijalog}

Matoš je često umjesto izravne polemičke reakcije znao napisati fiktivni dijalog u kojemu bi sudjelovala dvojica prijatelja, čija su gledanja na raspravljana pitanja frapantno podudarna s njegovim gledanjima na ista. Prvoga od te dvojice nazvao je Guravcem, a drugoga Rutavcem. Već ta njihova imena sugeriraju ,iskošenu perspektivu” gledanja na stvari oko sebe. Fiktivni dijalog Guravca i Rutavca Matoš uglavnom koristi kao pomoćno sredstvo u obračunu koji već traje. Dovoljno je zaviriti u tekstove naslova En marge (Matoš 1973b: 164-168), Literarne lakrdije (Matoš 1973b: 176-182), Literarni karneval (Matoš 1973b: 183-187), Literarni dijalozi (Matoš 1973b: 224-229) ili Borba s bikovima (Matoš 1973c: 24-27) pa da se uoči kako oni obično razgovaraju o pitanjima o kojima Matoš baš u tom trenutku polemizira i o ljudima s kojima se spori te da u pravilu dvojica prijatelja na kraju zaključe kako je „onaj Matoš” - unatoč svim objedama - jedini imao pravo.

Fiktivni dijalozi Guravca i Rutavca jedan su od načina literariziranja obračuna. Oni udvajaju istinsku polemičku reakciju i predstavljaju je kao neophodnu i vitešku. Postoje i dijalozi u kojima sâm Matoš s neimenovanim prijateljem komentira hrvatske književne prilike i ponašanje polemičkih protivnika. U njima iznosi pikanterije iz privatnog života svojih protivnika te se zajedno s prijateljem zgraža nad njihovim ponašanjem. On zapravo posredno „oslovljava” čitatelja nudeći mu mogućnost da se prepozna 
u njegovu anonimnom prijatelju i tako prikloni njegovoj polemičkoj istini. Stil je obje vrste Matoševih polemičkih dijaloga trivijalan, razgovoran, s puno svakodnevnogovornih klišeja, frazema i poštapalica.

\subsection{Humoreska}

Humoreska je jedan od načina fikcionalizacije polemike. Matošev polemički subjekt u njoj ludički je raspoložen, sklon jezičnim igrama i anegdotalnom govoru. Likovi i teme tih humoreski lako su prepoznatljivi i prosječnim poznavateljima tadašnjih književnih prilika. U kolovoškom broju „Savremenika” za 1911. Matoš tiska humoresku Discipulus. U njoj, ne spominjući mu ime, portretira mladog kolegu koji se iz učenika preobrazio u učiteljeva plagijatora i klevetnika. Kasnije se u liku Discipulusa prepoznao Tin Ujević, reagirao i polemika je mogla početi. Birajući priznati književni oblik za diskurzivni okvir konkretnom obračunu, Matoš je iznova potvrdio da svaki iskaz doživljava kao umjetničko očitovanje. Pišući humoresku, protivnika je pretvorio u literarnog junaka, predstavio ga tipom, primjerom jednog načina ponašanja te mu se nakon toga narugao.

Uz Discipulus, u diskurzivno ruho humoreske zaodjenut je i tekst Moderni simbol, alegorijska slika onodobne hrvatske književnosti kojom - prema Matošu - vladaju volovi. Glavni lik tog teksta sâm je Matoš koji se na početku ovako predstavlja:

„Bio sam sveti otac papa. Taman mi stadoše lizati papuče hrvatski hodočasnici pod vodstvom nekih crnorizaca, i ja padnem u pekmez.

- Hvaljen budi Jezuš Kristuš! - rekne neko u silnom basu, pa me probudi. Pored mene stoji grdan vol..." (Matoš 1973a: 15).

\subsection{Satira}

Još jedan oblik karnevalizacije polemike koji je vrlo oštar prema objektu osporavanja. Umjesto humora, u satiri dominiraju sarkazam i ironija. Budući da satiričar često negira kakvu stvarnu pojavu nalazeći da ona u potpunosti iznevjerava idealnu formu koju on ima na umu, satirički je subjekt prije pesimist nego optimist. Najuspjelija i formalno „najčistija” satira među Matoševim polemikama nosi naslov Silom-budala (Matoš 1973a: 179-184). Alegorijska je to slika Hrvatske i općih prilika u njoj. Autor Hrvatsku naziva „zemljicom 
Štreberijom”, njezinu prijestolnicu „Štreberovcem”, njezine političare „ubrnjičenim zemaljskim činovnicima", dok njezinim uvaženim stanovnicima podaruje imena poput „Prokop Poletek”, „Petko Prckendalj-Maljušić”, „Julijana Papendekel-Žemiček”, „Puvalo”, „Pipić-Pipičević”, „Tresislav Kiseli”, „Radivoj Frc”, „Bonaventura Nabijač” i sl. Taj tekst aludira na konkretne događaje i ljude. Priređivač knjige Dragi naši suvremenici Dubravko Jelčić nagađa da su među prozvanima Milan Marjanović, Milivoj Dežman Ivanov, Josip Pasarić, Vladimir Jelovšek, Josip Kosor, Marija Jurić Zagorka, Zofka Kveder i dr.

\subsection{Polemička pjesma}

Taj filološki terminus technicus označava književnu vrstu u kojoj se sukob mišljenja iznosi u stihovima koji se u pravilu rimuju. Epigram je kanonski oblik Matoševe polemičke pjesme. Samo u Dragim našim savremenicima nalazi se 183 epigrama. Matoš je, naime, običavao objavljivati po nekoliko desetaka epigrama odjednom, i to uglavnom u humorističkim časopisima. Zvao ih je „,štipcima”, ,živim epitafima”, „,koriandolima”, ,šipcima”. Njima je aludirao na pojedine mane svojih suvremenika, ismijavao knjige koje je kritizirao i autore s kojima je polemizirao. Njegovi epigrami najčešce su se sastojali od četiri unakrsno rimovana osmerca ili dva osmerca i dva šesterca, odnosno od dva rimovana dulja stiha. Evo četiriju Matoševih epigrama: u prvome pokazuje egocentričnost, u drugome iznosi zlobnu insinuaciju na račun pjesnika Domjanića, dok se u trećem i četvrtom obračunava s Tinom Ujevićem.

Nova knjiga

Neki A. G., teška brigo!

Izda knjigu opet.

Sad ga možeš, nadriknjigo,

Ako hoćeš - propet!

(Matoš 1973a: 222).

Jugoslaven

Domjanić nam oda tajnu modernizma svoga:

Prevode nam davat poče, znate, s madžarskoga...

(Matoš 1973a: 295). 


\section{Literarni Herostrat}

Da je Dostojevski zno tog sankilota,

Drukče bi napiso svog Idiota

(Matoš 1973a: 294).

Plagijatorče

Do sada bijaše August Ujević, Odsele će biti August Pfujević

(Matoš 1973a: 297).

Matošev je epigram u pravilu rugalica. Struktura mu se temelji na uočavanju kontrasta. Prividno povlađuje diletantskom, pučkom osjećanju stiha. Plod je prigodne imaginacije te nije uvijek lako otkriti njegov pravi povod.

\subsection{Aforizam}

U Matoševu polemičkom opusu nekoliko tekstova sastavljeno je isključivo od aforizama, npr.: Naprednjački katekizam (Matoš 1973b: 14-19), Novinarski cvjetići (Matoš 1973b: 28-31), drugi dio teksta Impromptu naslovljen Odgovor (Matoš 1973c: 40-55), Intimne misli (Matoš 1973c: 133-136), Intimni dojmovi (Matoš 1973c: 139-145) te Aforizmi i bilješke (Matoš 1973c: 149-151). Kao i u slučaju epigrama, Matoš različite ljude i događaje iz neposredne okoline „tretira” aforizmima koje reda jedan iza drugoga. Ti tekstovi zbog toga ne posjeduju tematsku, nego stilsku cjelovitost. Aforizam u njima iz stilskog postupka prerasta u samodostatni iskaz. U ilustraciju navodim, redom, prvih pet aforizama od njih dvadesetak koje je objavio u beogradskoj „Pravdi” u kolovozu 1911.

Biti glup nije nesreća, ali biti smatran glupim - jeste.

Ja ne vjerujem u Boga Oca, Sina i Svjatoga Duha, ali vjerujem u Bogdana, Grola i Skerlu.

Moja muza je toliko tužna, jer joj je nektar u "Srpskom književnom glasniku”, a amvrozija u dispozicijskom fondu.

Ja sam bermensch, moji protivnici su „untermenči”.

Da nema kiselih krastavaca, lubenice ne bi bile slatke (Matoš 1973c: 149). 
Kako se dade primijetiti, Matošev polemički aforizam najčešće ima klasičan oblik jedne prozne - sintaktički manje ili više razvedene - rečenice. Predstavljajući konkretno iskustvo kao opće pravilo, pisac aforizam stavlja u funkciju poopćavanja konkretnog sukoba.

\subsection{Dramski tekst}

U Matoševu polemičkom opusu samo jedan tekst u potpunosti oponaša dramsku formu uprizorujući izmišljeni razgovor više izmišljenih likova. Naslov mu je U Močvari, a izvorno je tiskan u „Hrvatskom pravu” 12.10.1907. U podnaslovu Matoš ga metatekstualno označava kao Dramski alegorijski razgovor s mnogo peripetija i tragičnom katastrofom. Na početku teksta - slijedeći diskurzivni kanon dramskog govora - navodi „likove” i mjesto nesvakidašnjeg razgovora:

Crvenperka (gospođica, namiguša strasnijeg škrga, inače hladna i brbljava);

Šaran (debelo momče, lijeno, ludo i bezuspješno zaljubljeno u vrajlu Crvenperčicu);

Trska (šuplja, vrlo vitka, melodijska i lirska dama, zaljubljena u Oblaka, visokog poetu, jako zgodna da se na njoj svira);

Oblak (elegijski lutalac, vječno „švorc”, u vječnim polemikama sa četiri Vjetra, uvijek gotov za grmljavinu ili za suze i - kišicu);

Događa se u Močvari, gradu jugoslavenske bistre kraljice Save (Matoš 1973b: 160).

Nedvojbeno je riječ o karnevalizaciji polemike. Matoševe obezljuđene osobe naklapaju da u toj Močvari (očita aluzija na tadašnju kulturnu klimu u Zagrebu) vladaju slabi - ,pigmeji, bakcili, infuzorije” koje Šaran i izravno imenuje Šimun Macura, Milan Marjanović, Ivan Lorković, Hinko Sirovatka. Isto je tako očito da se iza „Oblaka” krije sam Matoš koji na kraju razgovora - tjeran ,hladnim vjetrovima” - svima i svemu dovikuje oproštajno „Zbogom!”. Dramatizacijom polemičke reakcije Matoš iznova fingira razgovor anonimnih svjedoka svojih polemičkih sukoba i implicira kako su oni dakako na njegovoj strani.

\subsection{Polemička epistola}

Epistolom se obično nazivaju pisma pjesnika u kojima se raspravlja o filozofiji, književnosti ili moralu poput Ovidijevih Pisama s Ponta (Epistulae 
ex Ponto) ili Horacijevih Pisama (Epistulae). Polemičkom epistolom ovdje zovem polemički napadaj koji se ili pojavljuje u formi pisma ili tu formu oponaša - nadnevkom, oslovljavanjem protivnika, navođenjem tobožnjih novosti, potpisom itd. Česta su Matoševa pisma - obično naslovljena otvoreno pismo ili priposlano - upućena redakcijama pojedinih novina u kojima reagira na kakvu nezasluženu objedu, upozorava na zlonamjerno upotrijebljen podatak, neisplaćen honorar i sl.

Puno su zanimljivije epistole u kojima se Matoš obraća fiktivnom prijatelju (npr. Pismo iz Zagreba) ili se pak njemu obraća fiktivni pošiljatelj (npr. „Silom-budala”)". U njima izvrgava ruglu neke pojave i predrasude. Primjerice u Pismu iz Zagreba Matoš se obraća beogradskom prijatelju, aludirajući na srpski ekspanzionizam:

\section{Dragi Vujo.}

U srpskom našem Zagrebu već sam se sasvim sviknuo. Vi tamo u Beogradu imate slobodu i kralja, ali nemate ni čestitih nužnika. Ovde još ne vlada čika Pera i Skupština, ali nužnici su spram naših beogradskih ko crkve (Matoš 1973c: 34).

Tekst, pisan karikaturalnim srpskim jezikom, potpisan je s „Tvoj Djoka Čivija”. Obrazac pisma iskorišten je kao okvir ironične, prijetvornim govorom izvedene, invektive o jednom obilježju srpske politike. Matoševe polemičke epistole preoznačavaju intimistički diskurs privatnog pisma u njegovu suprotnost, te se ono uvijek pretvori u napad na primatelja.

\section{$* * *$}

Obilje diskurzivnih okvira u koje su se smještale polemičke reakcije ponajprije upućuju na Matoševu karnevalizaciju i fikcionalizaciju polemičkog govora. Na stanovit način radi se o oksimoronskom spajanju nespojivoga - polemike koja inzistira na načelu istinitosti i fikcije koja je indiferentna prema tom načelu. Izgleda međutim da stilist Matoš u umjetničkoj uvjerljivosti i vjerodostojnosti nalazi susretište polemike i fikcije te da u procesu

4 Taj tekst (Matoš 1973a: 12-14) naslovljen je kao i prije spomenuta Matoševa satira. Čak bi se mogao i tretirati satirom jer alegorijski slika i prokazuje svijet kojim vlada ljudska glupost. 
fikcionalizacije polemike želi nadići nesavršenu istinu pojedinačnih slučajeva. Pojedine je njegove polemičke tekstove doista moguće čitati kao umjetničke jer je istinu stavio u drugi, a umjetničku uvjerljivost u prvi plan.

\section{Totalni polemičar}

Zaključno se može kazati da se istinska vrijednost Matoševa polemiziranja dade iščitati iz dugogodišnje opredijeljenosti i spremnosti na „rat perom". Sporeći se sa svima i o svemu, nametnuo se kao autoritativan mislilac, vrstan stilist i nenadmašan zabavljač. Većina njegovih suvremenika, nemoćna obraniti se u izravnim sukobima, upala je u zamku te često na temelju polemičkog lica tendenciozno prosuđivala čitavo Matoševo djelo. Kako je među njima bilo mnogo uvaženih i utjecajnih ljudi, može se pretpostaviti da je Matoš polemičar i nehotice Matošu pjesniku „uskratio” mogućnost da za života (dapače, do 1923) objavi knjigu pjesama.

Hrvatska književnost njegova doba, ali i kasnija, puno toga duguje fascinantnoj Matoševoj energiji, upravo kultu borbe kojemu je pripisivao nastanak i čuvanje te energije. Pitanje koje se na koncu nameće glasi: Postoji li danas u Hrvatskoj pisac koji bi imao pravo izgovoriti rečenicu „U književnosti prijatelja nemam niti ih trebam!’?

\section{Literatura}

Aristotel, 1989, Retorika, prev. M. Višić, Zagreb.

Bagić K., 1999, Umijeće osporavanja. Polemički stilovi A.G. Matoša i M. Krleže, Zagreb.

Bagić K., 2012, Rječnik stilskih figura, Zagreb.

Bergson H., 1987, Smijeh (o značenju komičnoga), prev. B. Brlečić, Zagreb.

Čapek K., 1967, Dvanaest figura borbe perom ili priručnik za pismenu polemiku, u: idem, Marsija ili na marginama literature, prev. Ž. Jevtić, Beograd, str. 43-47.

Košutić-Brozović N., 1970, Evropski okviri hrvatske moderne, u: Hrvatska književnost prema evropskim književnostima, ur. A. Flaker, K. Pranjić, Zagreb, str. 345-363.

Krtalić I. (prir.), 1982, Polemike u hrvatskoj književnosti, sv. 1-5, Zagreb.

Krtalić I. (prir.), 1983, Polemike u hrvatskoj književnosti, sv. 6-10, Zagreb.

Matoš A.G., 1973a, Sabrana djela, sv. 12, Dragi naši savremenici, ur. D. Jelčić, Zagreb. 
Matoš A.G., 1973b, Sabrana djela, sv. 13, Polemike (1898-1908), ur. N. Mihanović, Zagreb. Matoš A.G., 1973c, Sabrana djela, sv. 14, Polemike (1909-1914), ur. V. Flaker, N. Mihanović, Zagreb.

Matoš A.G., 1988, Misli i pogledi, ur. M. Ujević, D. Jelčić, Zagreb.

Sloterdijk P., 1992, Kritika ciničkoga uma, prev. B. Hudoletnjak, Zagreb.

Šicel M., 1978, Povijest hrvatske književnosti, knj. 5, Književnost moderne, Zagreb. 